\title{
Synchrotron Radiation and Oil Industry Research
}

\author{
C. Pichon ${ }^{1}$ and J. Lynch ${ }^{2}$ \\ 1 IFP-Lyon, BP 3, 69390 Vernaison - France \\ 2 Institut français du pétrole, 1 et 4, avenue de Bois-Préau, 92852 Rueil-Malmaison Cedex - France \\ e-mail: christophe.pichon@ifp.fr - john.lynch@ifp.fr
}

\begin{abstract}
Résumé - Rayonnement synchrotron et recherche dans l'industrie pétrolière - Du fait de ses propriétés particulières, le rayonnement synchrotron est un outil de caractérisation puissant permettant l'obtention d'informations spécifiques dans de nombreux domaines scientifiques et, en particulier, dans le domaine de l'industrie pétrolière.

Cet article d'introduction au dossier «Utilisation des grands instruments analytiques dans l'industrie pétrolière » propose une approche rapide et concrète de l'outil synchrotron, de ses propriétés et de ses applications dans toute la chaîne pétrolière (du puit de pétrole aux produits raffinés).
\end{abstract}

\begin{abstract}
Synchrotron Radiation and Oil Industry Research - Because of its unique properties, synchrotron radiation is a powerful tool for characterisation from which it is possible to obtain specific information in various scientific domains and, in particular, in the field of the oil industry.

This introductory article to the dossier "Synchrotron and Neutron Solutions to Oil Industry Problems" proposes a brief but practical overview of synchrotron radiation as a tool, of its properties and of its applications in the hydrocarbon industry (from oil well to refined products).
\end{abstract}




\section{INTRODUCTION}

Although not strangers to each other, synchrotron radiation and the oil industry represent, apparently, two very different worlds.

Known since antiquity as a light source or a way to protect wood against insects and seawater, crude oil started to be a real industrial product on August $27^{\text {th }} 1859$ with the first drilling of oil wells in Pennsylvania. With the apparition of the car industry, at the beginning of the $20^{\text {th }}$ century, the oil refining industry was created and quickly rose to be one of the major human activities around the world. Highly strategic, the oil industry drains colossal funds, employs many people around the world and associates very different activities (exploration, reservoir engineering, drilling, production, refining, petrochemicals, engines and energy) from the oil-well to the car. Often based on chemistry, it aims at the transformation of a raw material into refined useful products.

Synchrotron radiation is, for its part, more recent and experienced a rapid expansion during the second half of the $20^{\text {th }}$ century. Nowadays, synchrotron radiation is considered as one of the most powerful instruments for physicalchemistry characterisation of products and materials. Biochemistry [1,2], materials science [3-5], product characterisation [6-9], nanotechnology [10,11], catalysis [12-15] are, in particular, fields of activities for which several applications implying synchrotron radiation can be found.

In spite of the increasing interest of synchrotron radiation for the research activities in the field of oil industry [5, 8, 9, 12-15], the difficult access to the instrument, linked to its rarity, is one of the reasons why synchrotron radiation is not, at the present time, used on a routine basis, being reserved to more fundamental activities in research in the field of oil industry.

But, with the $21^{\text {st }}$ century, and the rarefaction of petroleum reserves, the time has arrived to enhance the value of each atom of carbon of each oil drop. The consequence of such an increase of the value of crude oil is of course a need to enhance of our knowledge, if possible down to an atomic scale, of oil products and catalysts. Here, the use of synchrotron radiation, and, more generally, the use of large instruments, including research nuclear reactors (see article by $\mathrm{H}$. Jobic and A. Méthivier in the current issue), can be very useful because of the wide ranging and powerful analytical information they provide.

The main aim of this article is to introduce the Oil \& Gas Science and Technology thematic dossier "Synchrotron and Neutron Solutions to Oil Industry Problems", in which a wide range of scientific themes and techniques are tackled. As a conclusion to the dossier, a final article dedicated to a new third generation synchrotron source, SOLEIL, is presented. The following articles make up the dossier:
- 3D Quantification of Pore Scale Geometrical Changes During Carbonate Sample Dissolution, by D. Bernard;

- Synchrotron FTIR Hydrocarbon Fluid Inclusions Microanalysis Applied to Diagenetic History and Fluid Flow Reconstruction in Reservoir Appraisal, by N. Guilhaumou and P. Dumas;

- EXAFS Characterization of New Active Phases for Catalytic Hydrotreatment Catalyst, by C. Thomazeau, C. Geantet, M. Lacroix, M. Danot and V. Harlé;

- Kinetics of Sulfidation of Hydrotreating Catalysts Doped with Organic Additives Using In Situ EXAFS Spectroscopy, by C. Geantet, M. Lacroix, P. Mazoyer-Galliou, F. Diehl and C. Pichon;

- Nature of the Interactions between the Metallic Part of an Industrial Bimetallic Pt-Rh Post Combustion Catalyst and the Support, by F. Maire, D. Bazin, S. Schneider, H. Dexpert, G. Meunier, F. Garin and G. Maire;

- Structure and Size of Bimetallic Palladium-Platinum Clusters in an Hydrotreatment Catalyst, by D. Bazin, D. Guillaume, C. Pichon, D. Uzio and S. Lopez;

- Molecular Diffusion in Zeolites Studied by Neutron Scattering Techniques, by H. Jobic and A. Méthivier;

- Toward operando Characterisation by Powder Diffraction Techniques of Molecular Sieves, by C. Pichon, H. Palancher, J.L. Hodeau and J.F. Bérar;

- SOLEIL a New Powerful Tool for Material Science, by F. Baudelet, R. Belkhou, V. Briois, A. Coati, P. Dumas, V.H. Etgens, A.M. Flank, Ph. Fontaine, Y. Garreau, O. Lyon, I. Quinkal, F. Rochet, P. Roy, M. Sauvage, F. Sirotti, A. Somogyi and D. Thiaudière.

In this introductory article we focus on the most widely used large instrument: the synchrotron. After a short presentation of synchrotron facilities and synchrotron radiation, we present the future challenges in the field of characterisation of oil products and catalysts and we show how synchrotron radiation can be use to obtain information in a specific, original and complementary way compared to convention analytical tools.

\section{WHAT IS A SYNCHROTRON AND WHAT IS SYNCHROTRON RADIATION?}

\subsection{Synchrotron and Synchrotron Radiation: a Short Historical Review}

A long time after the discovery of X-rays by Roëntgen in 1895, the first synchrotron radiation was observed in 1947 in the General Electric synchrotron by Elder et al. [16]. Since first generation synchrotron facilities were first build for high energy physics and collision science, the synchrotron radiation was, at the beginning, considered as a parasitic phenomenon because it causes the accelerated particles (electrons) to lose energy. 
However, some experimental investigations of the properties of the synchrotron radiation were carried out in the late 1940's [17-20], and opened the way to characterisation by spectroscopy using synchrotrons [21, 22]. During the 1970's, as new storage rings were built for highenergy physics research (for example, DCI and ACO in France) and as the interest for this type of research increased, more and more studies, implying synchrotron radiation and based on a growing number of techniques, began. At the same time, and in relation with the increase of the synchrotron beam-time available for scientists, new characterisation techniques appeared or re-appeared around the storage ring. This was the case for X-ray absorption spectroscopy, and more particularly for EXAFS spectroscopy, experimental evidence of which was know for a long time [23, 24], and which found a new development with the work of Sayers et al. [25].

With the increase of the interest for synchrotron radiation, second-generation sources, built to be dedicated to synchrotron radiation research, appeared around the world (SRS in Daresbury, UK, 1980; NSLS in Brookhaven, USA, 1981; Photon Factory in Tsukuba, Japan and BESSY in Berlin, Germany, 1982, etc.). At the same time, major progress was made in the 1980's in developing optics, instruments and techniques in the UV and X-ray spectral range. The presence of such new and powerful capabilities led to a tremendous expansion of the research fields: condensed matter physics, material sciences, chemistry, biology, environmental science and electronics. Secondgeneration synchrotrons represented a tool well adapted to improve our understanding of nature.

The increase of the interest for higher spatial, temporal and energy resolution which was a driving force lead to the construction of a third-generation synchrotron radiation sources during the 1990's which were conceived around newly invented high-brightness undulator devices [26, 27]. At present, three third-generation synchrotron are in operation around the world (ESRF, Grenoble, France; Spring 8, NishiHarima, Japan; APS, Argonne IL, USA) and many others are under construction (SOLEIL, Orsay, France; DIAMOND, Didcot, UK; LLS ALBA, Barcelona, Spain, etc). More information about the SOLEIL synchrotron is available in the closing article of this dossier (by F. Baudelet et al.).

At the same time, the development of fourth-generation synchrotrons, represented by the free electron laser (FEL) source is on the march [28] and a FEL operating in the hard $\mathrm{X}$-ray domain is under construction in Hamburg $[29,30]$.

\subsection{General Description of the Machine}

When high-energy charged particles, such as electrons, positrons or ions, travelling at relativistic energies (i.e. with a speed close to the speed of the light in vacuum), are deflected by an appropriate magnetic field, the energy loss induced by the acceleration of the particle is compensated for by the emission of electromagnetic radiation tangential to the orbit of the particle (see Fig. 1). This radiation is called synchrotron radiation.

Generally speaking, recent synchrotron facilities use electrons as high energy particles to produce synchrotron light (some second generation synchrotron facilities are operated with positrons). To produce synchrotron light, synchrotron facilities are composed of:

- An electron gun which produces bunches of electrons from a metallic foil [31, 32].

- Several accelerators (first a linear accelerator and then a roughly circular booster) which accelerate the bunches of electrons to a speed close to the speed of the light $[33,34]$.

- A storage ring where the accelerated bunches of electrons travel in a roughly circular orbit and where they emit synchrotron light [35]. A booster linked to the storage ring via an injection device allows reloading of the storage ring with accelerated bunches of electrons.

- Several beam-lines, which are beam channels attached to the storage ring and allow the synchrotron light to be conditioned and used on various experimental stations [36-43] (see Fig. 2).

A beam-line, the most important device of the synchrotron facility from a user's point of view, materialises the optical path of the synchrotron radiation from the storage ring to the experimental station. Typically, it consists of:

- Various optic devices which aim at the definition of the size (slits), of the energy or the wavelength (monochromator [44, 45]) and of the focussing (mirrors [46, 47]) of the beam.

- The experimental station itself. Depending on the nature of the experiment (diffraction, scattering, absorption, tomography, photoemission, etc.), various elements can be found on an experimental station (goniometer, diffractometers, sample holders, detectors, etc.).

An example of a beam-line is given in Figure 3 ( $a$ and $b$ ).

\subsection{Synchrotron Light}

In the early 1960's, as synchrotron radiation was no longer considered as simply a nuisance in high energy physics phenomena, its exceptional properties were studied and used for various analytical purposes. The basic equations describing synchrotron radiation are well know and will not be discussed in this article (extensive information can be found elsewhere [49-53]).

From the analysis point of view, synchrotron radiation has several important properties [54-57]:

- high intensity with storage rings emitting from several $\mathrm{kW}$ to several MW of synchrotron radiation;

- broad spectral range covering a continuum from the infrared to the hard X-ray region; 


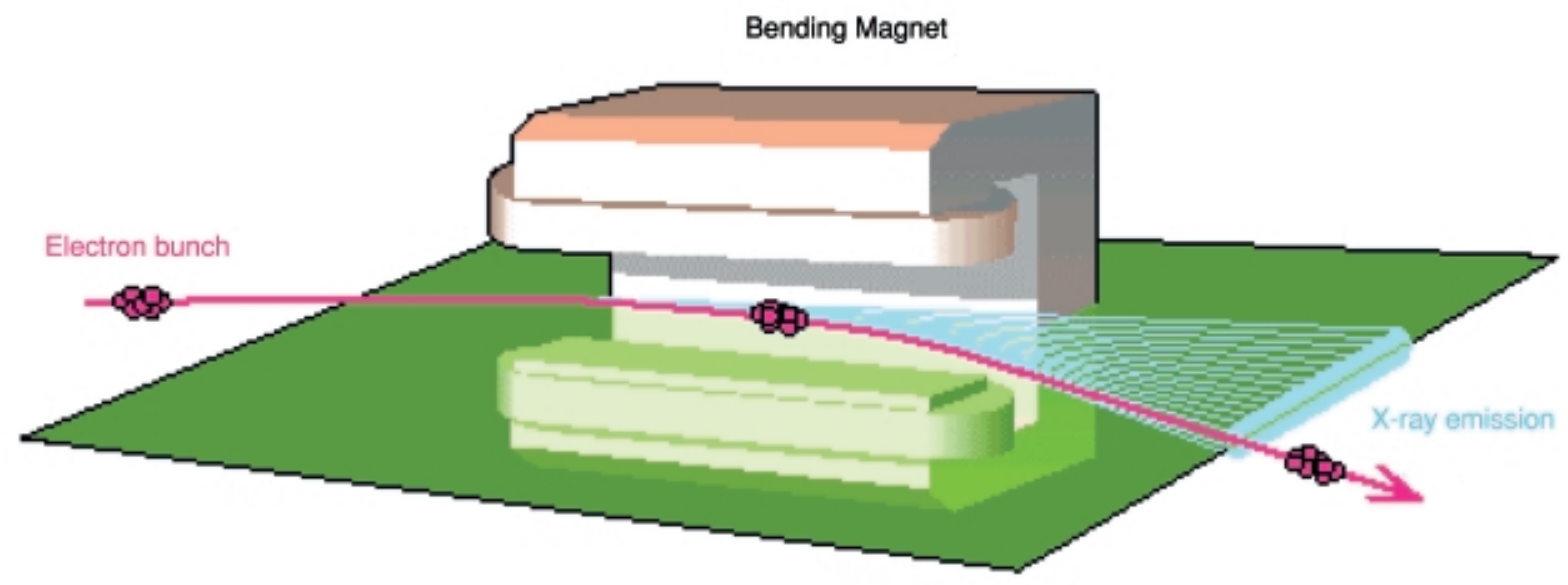

Figure 1

Emission of synchrotron light from bending magnet [48] (reproduced with permission from ESRF).

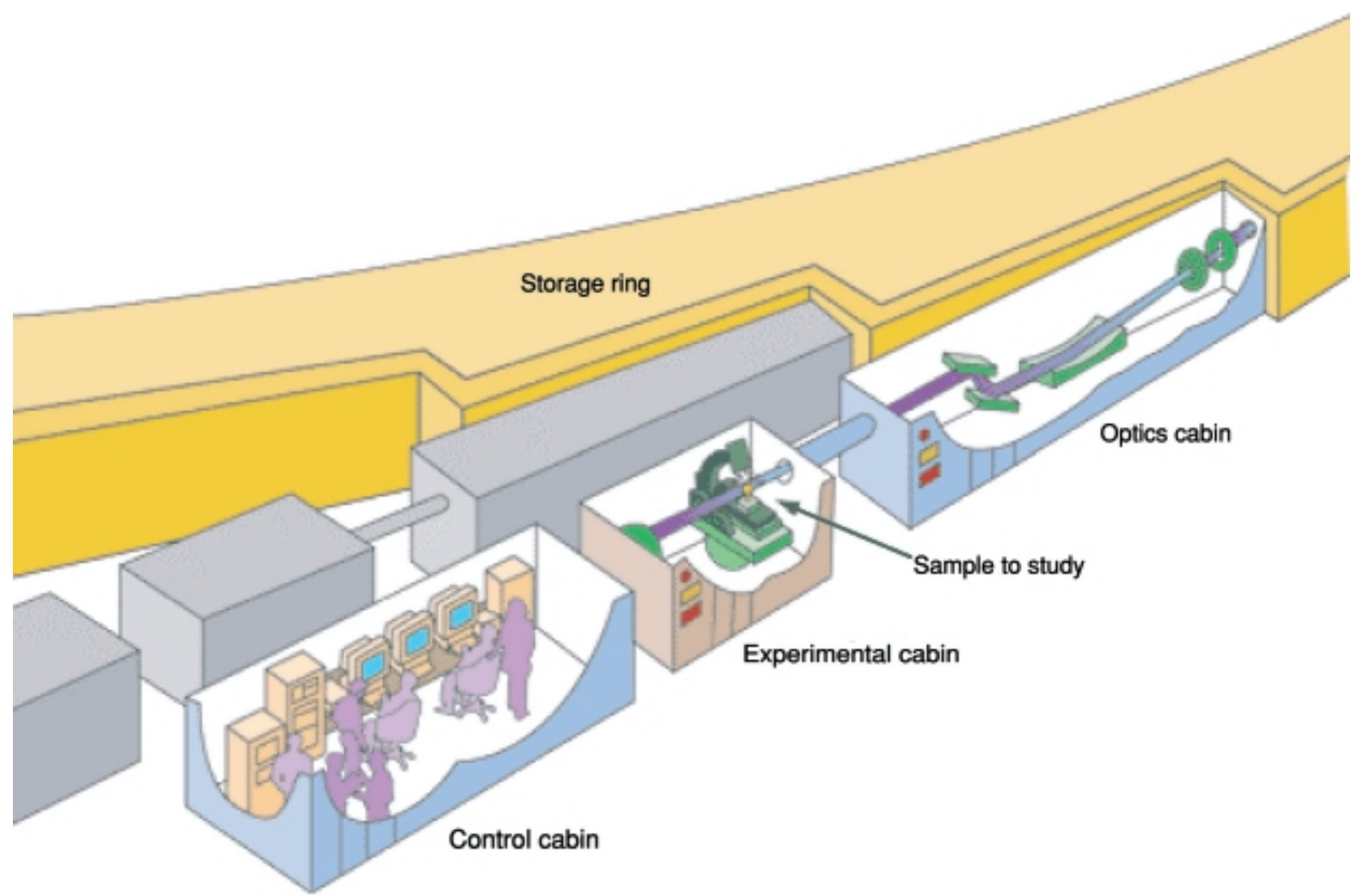

Figure 2

Synchrotron beam-line [48] (reproduced with permission from ESRF). 


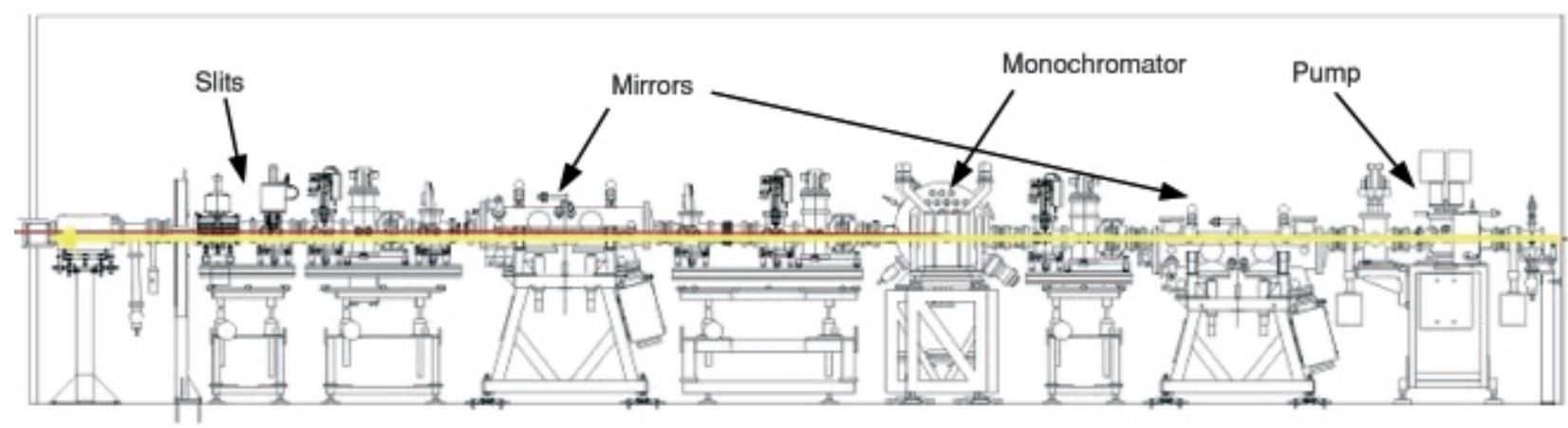

Figure 3a

BM16 Optical hutch of the ESRF [48] (reproduced with permission from ESRF).

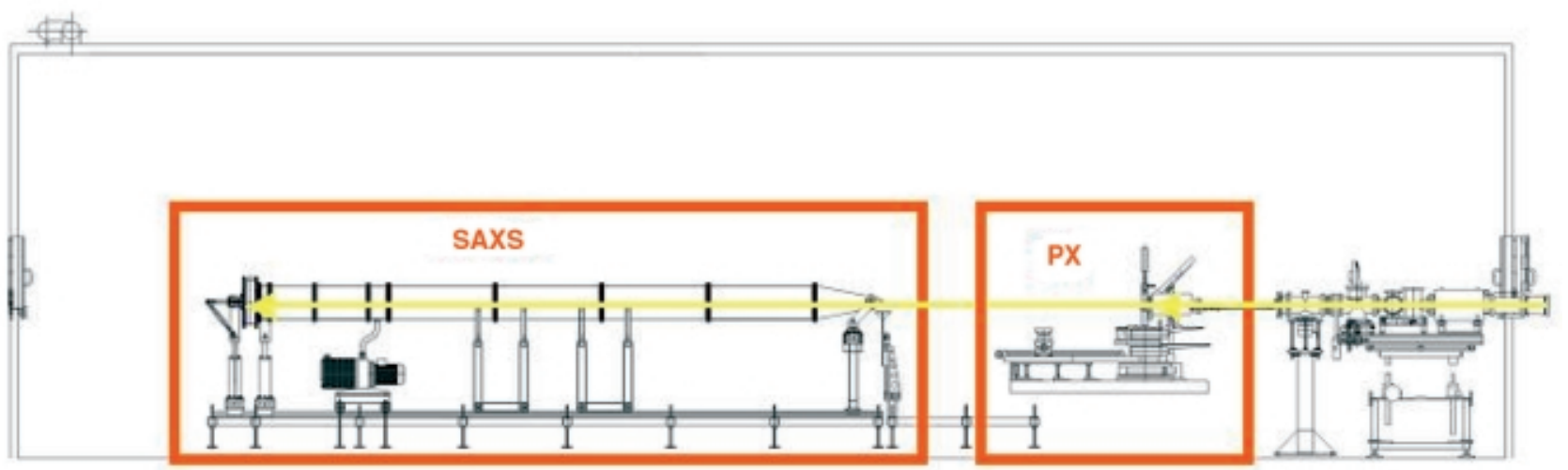

Figure $3 b$

BM16 experimental hutch of the ESRF [48] with the Small Angle X-ray Scattering station, SAXS, and the Protein and macromolecular crystallography station, PX (reproduced with permission from ESRF).

- natural high degree of collimation in the range of $1 \mathrm{mrad}$ to $0.1 \mathrm{mrad}$;

- high polarisation which is completely linear in the plane of the orbit;

- pulsed time structure with a pulse duration as short as $50 \mathrm{ps}$;

- small source size from several square millimetres to a few tens of square micrometres;

- high degree of stability of the synchrotron beam because of the high stability of the electron beam in the storage ring (linked with the high quality of the vacuum in the ring).

With such properties, synchrotron radiation first appears to be a high brightness source of photons (defined as the flux of photons per unit area of the radiation source per solid angle of the radiation cone per unit spectral bandwidth).
In the $\mathrm{X}$-ray region, synchrotron radiation is from $10^{4}$ to $10^{14}$ times more brilliant than an X-ray beam from a conventional sealed X-ray tube used in a laboratory (see Fig. 4). The superior spectral brilliance of the beams of photons from a third-generation synchrotron radiation source can be a critical element for success for frontier experiments that can require very high resolution in energy, in time or in space. It is also of great help in the field of in situ experiments where it allows rapid recording of data.

A second advantage of synchrotron radiation over conventional X-ray sources is that it is a tuneable X-ray source. This unique property of synchrotron radiation opens the field of X-ray spectroscopy and can for instance help to eliminate, by an appropriate choice of the working energy, parasitic phenomena (such as X-ray fluorescence in an X-ray diffraction experiment). 


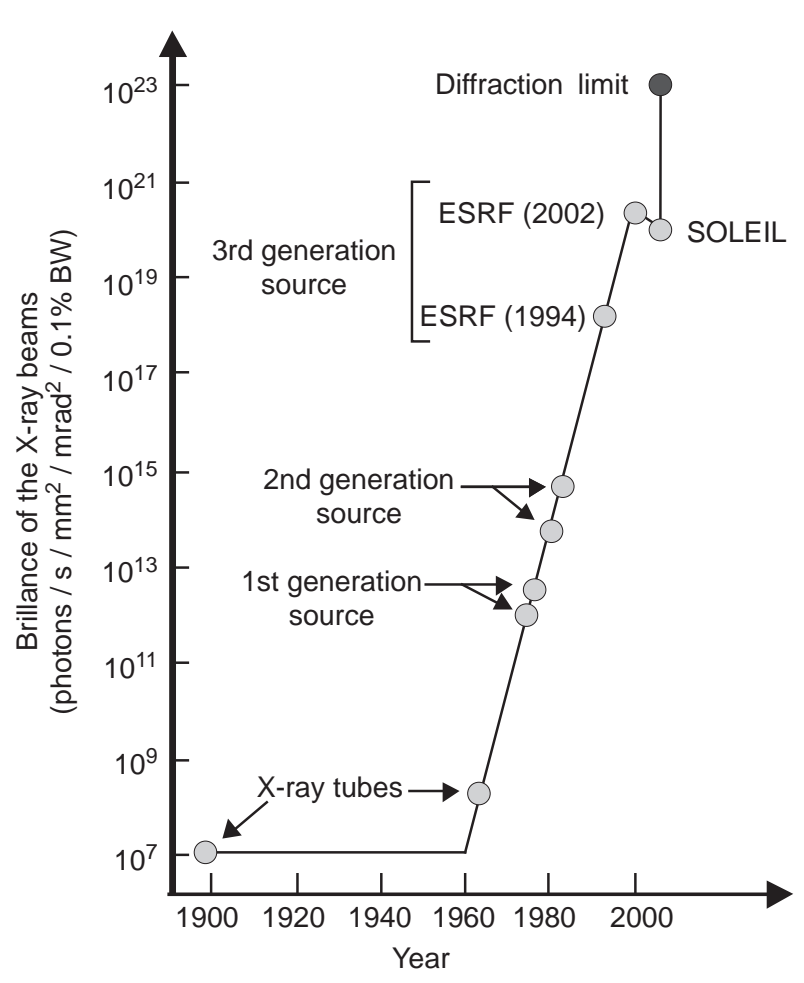

Figure 4

Brilliance of the X-ray beams.

\subsection{Properties of Synchrotron Light and Analytical Techniques}

The specific properties of synchrotron radiation allow specific techniques that can bring complementary information. In particular, and if we focus on key properties, it appears that:

- The energy continuum of synchrotron radiation allows specific diffraction or spectroscopy techniques such as anomalous X-ray diffraction, X-ray absorption spectroscopy: XANES and EXAFS (see articles by C. Thomazeau et al., C. Geantet et al., D. Bazin et al. and C. Pichon et al. in this issue).

- The high brilliance of synchrotron radiation improves the efficiency of some analysis techniques such as small angle $\mathrm{X}$-ray scattering (SAXS) and powder X-ray diffraction, and opens the way to in situ characterisation, timeresolved studies with small characteristic times and characterisation of fragile materials (proteins for example). Articles by C. Geantet $e t$ al. and by C. Pichon et al. in the current issue deal with in situ characterisation.

- The high brilliance together with the possibility to obtain a small source size and a natural high degree of collimation of the beam allow specific applications such as topographic studies (mapping of the samples) and $\mathrm{X}$-ray or infrared microscopy (see articles by D. Bernard and by N. Guilhaumou and P. Dumas in this issue).

Just as it is not the only way to produce radiation, the synchrotron is not the unique solution to study an interaction between radiation and matter and, of course, a lot of recent and important scientific studies do not imply synchrotron radiation. However, in the field of atomic and molecular physics, synchrotron radiation offers unique possibilities (linked to its unique properties) to characterise a wide range of properties such as binding energies and their shifts with molecular environments, energetic and atomic structures and their evolution during dynamic processes, etc.

\section{SYNCHROTRON RADIATION APPLIED TO THE OIL INDUSTRY}

Research in the oil industry addresses a vast range of problems and needs to include contributions from many disciplines. The complexity of the industry has evolved enormously over the last few decades, in response to contrasting (indeed partially contradictory) global trends towards an increase in consumption coupled with increasing concerns over impact on climate and the ultimate limitation of world resources. The increased use of high technology solutions has become essential to identify new sources, to maintain the production of existing fields, and to ensure the transformation of crude oil into an ever-cleaner energy source.

\subsection{Exploration}

Prediction of the likely target areas in which to search for crude oil is greatly improved by the study of the geochemical history of an area. Laboratory techniques, such as optical and electron microscopy and X-ray diffraction (XRD), provide the bulk of the information needed. Synchrotron radiation techniques can however improve our knowledge of source rocks, for instance, by infrared microscopy analysis of fluid inclusions (see the article by N. Guilhaumou and P. Dumas in the current issue). Trace element analysis of crude oil can help to determine the path followed by oil during its migration. Highly sensitive elemental analysis techniques exist in synchrotron radiation centres, but here chromatography and mass spectrometry, providing information on speciation and isotopic abundance, are far more developed [58].

Hydrates of natural gas may represent an enormous untapped reserve for the future. As we shall see, hydrates are also an important topic in the transport of oil. Identification of hydrate reserves by seismic exploration relies on knowing the response of these solids to acoustic waves, i.e. their mechanical properties. Inelastic X-ray scattering is one of the 
techniques under evaluation to determine the vibrational response of hydrates as a function of their structure [59]. Determining the conditions for formation and preservation of hydrate structures, in order to identify promising areas for exploration, is also an active topic of research. The experiments required involve acquisition of X-ray diffraction patterns under high pressure at low temperatures: conditions that can be achieved in laboratory XRD set-ups but for which the use of high-energy synchrotron radiation allows much flexibility [60].

\subsection{Reservoir Engineering}

The key topic here is fluid transport in porous media. Oil and gas displacement in reservoirs over scales of several tens of kilometres may be strongly affected by phenomena at the fluid/rock interface. In particular, preferential wettability of rocks by oil or water affects the amount of oil that remains trapped in place after extraction. The nature of the rocks can be determined in the laboratory by optical microscopy and $\mathrm{X}$-ray diffraction, whilst electron microscopy provides the morphology and composition. By freezing and sectioning samples, 2D images of fluid distribution in rocks can be obtained using cryo-microscopy. However, for 3D in situ studies of the distribution and flow of oil and water in oil-wet and water-wet matrices, microtomography is likely to provide key information [61]. Figure 5 illustrates the complementary nature of high spatial resolution 2D information from cryo-microscopy and the 3D studies possible with microtomography (see also the article by D. Bernard in this issue).

\subsection{Drilling}

Future oil discoveries are likely to involve drilling at depths of several kilometres, implying conditions of high temperature and high pressure that have rarely been explored up to now. In addition to the challenge of developing electronic components capable of withstanding these conditions, so as to ensure monitoring and guidance of the drilling head, the drill bit needs to withstand both the static conditions and the shocks from contact with the rocks. New materials are being tested for their improved performance [62]. Speciality cements are already in use to reinforce the well walls and to seal them against water intrusion. Under the extreme conditions encountered and given the long exploitation times required, cement ageing is a key problem, studied for instance by electron microscopy and molecular spectroscopy [63]. Understanding transformation mechanisms under extreme conditions is thus another area in which synchrotron radiation studies can help to determine the factors limiting materials performance and in suggesting where the improvements could be made.

\subsection{Transport}

Pipelines increasingly transport complex mixtures of fluids (oil, water, gas and sand) from the prevailing high
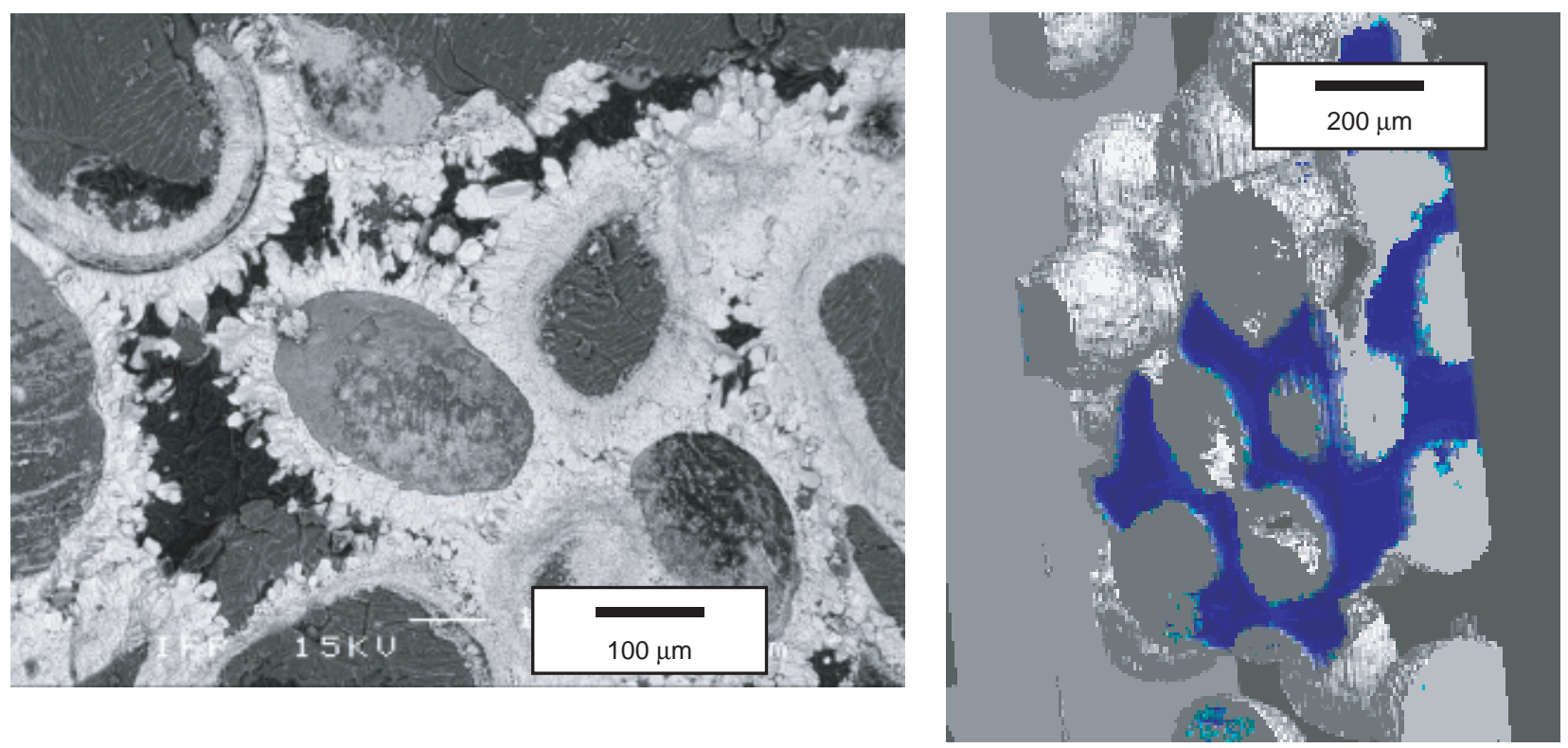

Figure 5

Electron cryo-micrography (left) and X-ray microtomography (right) images of fluids in porous media (Courtesy E. Rosenberg). Cryomicroscopy shows the detailed distribution of oil (black) and water (grey) in a cross section of limestone (white). X-ray microtomography has lower spatial resolution but allows a 3D view (here of water trapped by non-wetting silica beads). 
temperature and high-pressure conditions of reservoirs through, for example, seabed networks. Interruptions to flow may cause cooling of the fluid to seabed temperatures and the resulting crystallisation of hydrates or aggregation of asphaltenes (or other organic components) can lead to pipe blockages. This is another area in which it is essential to identify hydrate formation conditions, as well as to study the effects of hydrate inhibitors [64]. Asphaltene association can be studied by light or X-ray scattering and, in a nuclear research centre, by neutron scattering [65]. Small angle X-ray scattering in particular can give information on the size and form of aggregates. Using the high intensities and rapid acquisition times available with synchrotron radiation can help in establishing kinetics of the process.

Work is also under way in developing solutions for effective long-term insulation, involving for example the use of phase change materials or of syntactic foams [66]. The latter can be exposed to corroding seawater, so that knowledge of the materials response to this type of environment over long periods is essential to flow assurance. Post-mortem investigations reveal some information on the processes involved, but recent studies using synchrotron radiation microtomography to study foam structures [67] promise to provide more directly interpretable data.

Emulsion transport of heavy oils has been proposed as an option to decrease transport costs [68]. The formation and stability of these emulsions, as well as procedures to break up the emulsions after delivery, need to be studied both by rheological methodologies and by small angle scattering. Although microscopy and laboratory SAXS methods have been available for some time and provide useful information [69], small angle neutron scattering in deuterated solvents can improve the contrast [70] and synchrotron radiation studies allow kinetic data to be obtained both by SAXS and transmission X-ray imaging [71].

Transport and storage of natural gas and refined products in pipes and reservoirs also present materials problems. With increasing concerns for environmental protection, diffusion through containers must be prevented. Nanostructured polymer-clay composites are good candidates for a new generation of low permeability materials but structural and textural information must be obtained and correlated to resulting properties. For the moment, much of this information is obtained via electron microscopy, requiring thin film sections to be made. X-ray microtomography promises to provide information in a non-destructive manner on the microtexture of these composites [72].

For the coming generations, transport and storage of hydrogen may be as great, if not a greater problem than that of organic fuels. Again, low permeability compounds need to be developed for pipes and reservoirs. New lightweight materials need to be developed to contain hydrogen in a compact manner if its use for transport is to be generalised. The most promising systems are low molecular weight reversible hydrides. Hydride formation can be followed by laboratory and synchrotron XRD and by neutron diffraction [73] and modern facilities have a key role to play in following the formation kinetics and the subsequent phase changes due to "charging-discharging" cycles.

\subsection{Refining and Petrochemistry}

Crude oil is a complex mixture of many hydrocarbons, and it is the detailed local environment of the carbon atoms that determines the reactivity of these organic compounds. Gas chromatography and mass spectroscopy are therefore here
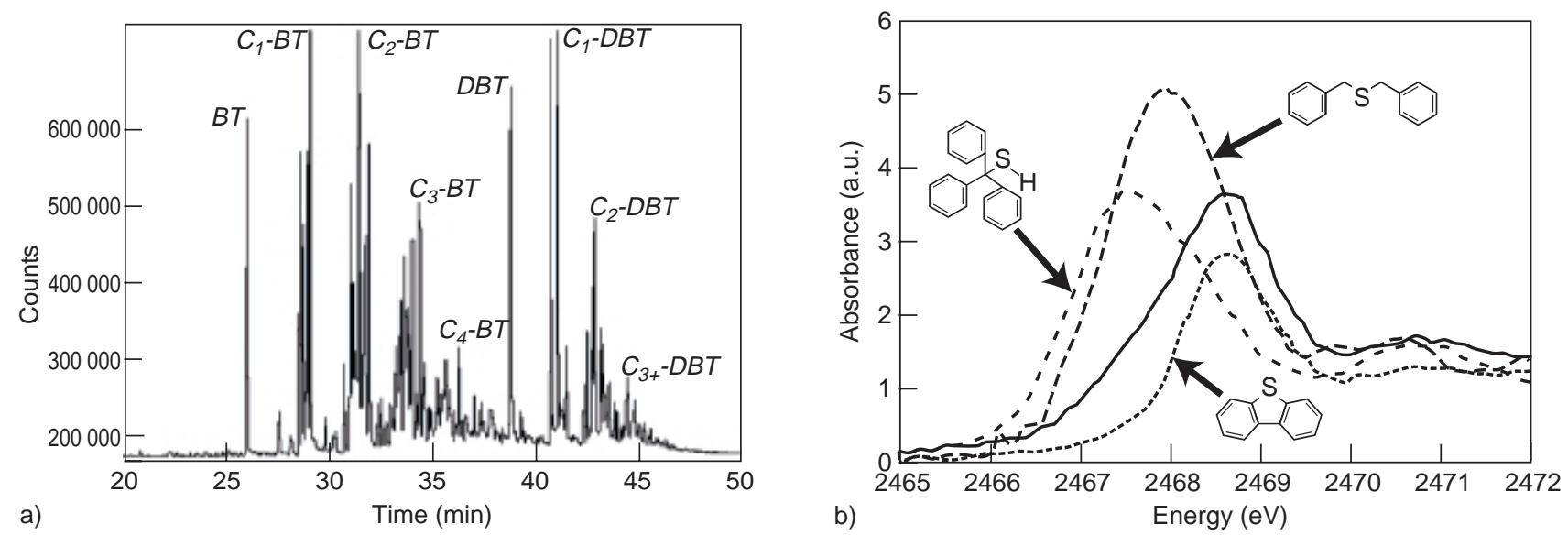

Figure 6

Studies of sulphur environments in petroleum cuts by gas chromatography (a) and X-ray absorption (b). In the former, dibenzothiophene (DBT) and its alkyl derivatives are identified individually in a liquid cut. In the latter, an asphaltene deposit (solid line) is compared to polyaromatic reference compounds (dashed lines). 
again the main techniques. One opportunity for element specific synchrotron radiation techniques is in studying the hetero-elements in the heavier oils [74], where molecular identification is difficult. XANES has been able to provide clues as to the local co-ordination of $\mathrm{S}, \mathrm{N}, \mathrm{Ni}$ and $\mathrm{V}$. Elimination of these elements in refining is of major environmental importance. Figure 6 illustrates the detailed analysis of low molecular weight sulphur compounds obtained by gas chromatography with a sulphur specific detector [75] and the information available from X-ray absorption-the latter is less detailed but can be obtained on solid heavy oil deposits.

Catalysts and zeolites are largely covered in this issue. They are "prototype" nanomaterials, having been made by controlled chemical interactions before the current interest for designer nanomaterials gained ground. The evaluation of catalysts depends still to a great extent on model reactions: even with today's enormous range of investigation techniques, quantitative structure-reactivity relationships are difficult to establish. Recent progress in molecular modelling, helping to correlate atomic scale description and macroscopic reactivity, provides hope that such relationships might be achieved in the near future [76].

The supports of heterogeneous catalysts are important players in refining and petrochemistry, providing large surface areas to disperse the active phase as well as porosity to allow reactants to diffuse to, and products to diffuse from, the active sites. To achieve large surface area, supports are typically made from poorly crystallised oxides. This lack of organisation, coupled with the fact that low atomic number oxides such as alumina or silica are the most common, means that molecular spectroscopy techniques (NMR and IR) are the most frequently used to obtain details of the local environment [77]. In many cases of supported metal catalysts these techniques can be complementary. Figure 7 compares spectra of cobalt $/ \mathrm{SiO}_{2}$ Fischer-Tropsch catalysts after reduction and after contact with water (a by-product of the FischerTropsch reaction). X-ray absorption provides bulk information showing a tendency to form a local structure similar to cobalt silicate. Infrared spectroscopy of absorbed $\mathrm{CO}$ molecules, IR(CO), shows that new surface sites are formed, due to isolated cobalt atoms. The combined information gives a clear picture of the structural changes: insertion of $\mathrm{Co}$ atoms into the surface layer of the silica support.

Zeolites are a case apart: used both as supports and as acid catalysts in their own right, their large internal surface area as a result of long range order which can easily be studied by $\mathrm{XRD}$. The acid function is however again a result of local $\mathrm{Al}$ and $\mathrm{Si}$ co-ordination. Laboratory techniques such as NMR and IR are most often employed in these studies [78].

In the field of supported catalysts, laboratory and synchrotron radiation methods have achieved important synergy in identifying structural and electronic characteristics. In heterogeneous catalysis, laboratory structural studies by electron microscopy and X-ray diffraction reveal information on the structure of solids containing short and long range order respectively [79]. The complex nature of modern catalysts, containing several phases acting either as active catalyst components or as support (or contributing to both simultaneously) can render investigation of the supported phase (often a highly divided precious metal or alloy) difficult, due to superposition of information from the different structures present. These studies are clearly aided by element specific synchrotron radiation techniques such as EXAFS [80] and both small-angle [81] and large-angle [82] anomalous X-ray scattering. The electronic information
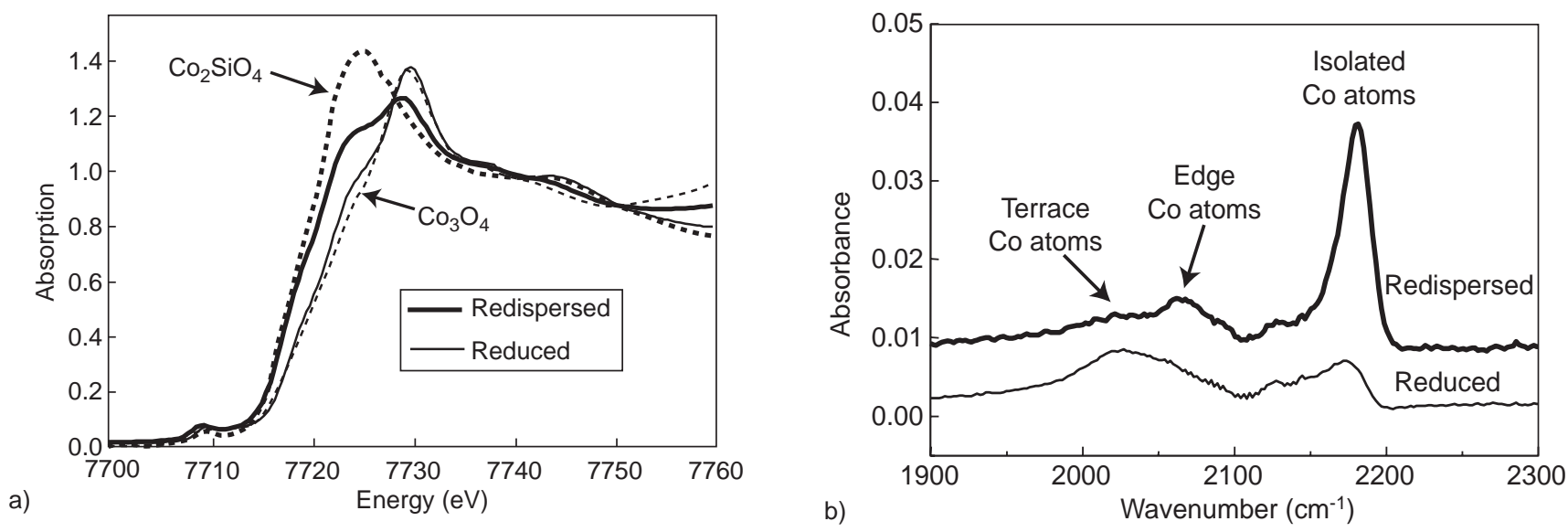

Figure 7

$\mathrm{Co} / \mathrm{SiO}_{2}$ Fischer-Tropsch catalysts in reduced and redispersed states. X-ray absorption (a) shows a progression towards cobalt silicate type structure on redispersion whereas IR spectroscopy of adsorbed $\mathrm{CO}$ (b) reveals the formation of isolated Co atoms. 
provided under vacuum in the laboratory by XPS can be enriched by in situ studies using synchrotron radiation: both by the well-established near edge spectroscopy and by the developing high-energy XPS technique [83]. In addition, near edge spectroscopy can be applied to homogeneous catalysis systems to follow changes in the configuration of the metallic centre [84].

For zeolites used in petrochemical applications, such as isomer separation, details of the structure, in particular on the exact positions of the cations and their interaction with organic molecules, are of prime importance. Laboratory XRD is able to provide sufficient information to locate a single type of cation but for more complex solids synchrotron radiation anomalous XRD is required (see article by C. Pichon et al. in this issue). Location of the organic molecules can be more easily achieved with neutron diffraction. NMR and inelastic neutron scattering can provide, each on its own time scale, information at the scale of the atomic cage on the diffusion of molecules (see article by H. Jobic and A. Méthivier in this issue). Once again, molecular modelling can provide a key link between this atomic scale description and the performance of the solids.

\section{$2.6 \mathrm{CO}_{2}$ Sequestration}

Reducing the environmental impact of industrial activity is a major challenge to modern society in which the petroleum industry is a key player. In addition to the production of cleaner, low carbon fuels, capturing the carbon dioxide produced during fuel use can reduce the impact on the atmosphere. Underground sequestering of $\mathrm{CO}_{2}$ in depleted wells is one option that needs to be considered, but predicting the fate of the sequestered gas involves studies of gas-waterrock interactions in reservoir conditions. The same is true for prediction of the behaviour of the cement seals used to close wells into which the gases will be injected. Laboratory studies using XRD or electron microscopy, for instance of phase transitions and precipitation, can once again be complemented by in situ synchrotron radiation XRD and microtomography [85].

\section{CONCLUSION}

For almost 60 years, synchrotron facilities have been providing high quality analytical tools for many scientists in various fields of activities. With research nuclear reactors, they from the group of shared scientific tools known as "large instrument facilities".

Considered at the beginning as a parasitic phenomenon, synchrotron radiation is, at present, one of the most important sources of photons. The main reason for this evolution is the exceptional properties of the synchrotron radiation as both a brilliant and an energy tuneable source of photons.
With the rise of third-generation synchrotron facilities, some extreme experiments become possible. The field of possible applications is quickly growing and matches more and more often with the requirements and challenges of various scientific and industrial fields of activity.

Materials challenges in the oil industry have become more critical as "high technology oil" is replacing conventional crude sources and environmental concerns take the centre stage. From exploration through refining to $\mathrm{CO}_{2}$ storage, numerous research challenges have to be met, in which the information from large instrument facilities is an important contribution to the solutions.

\section{REFERENCES}

1 Pinheiro T., Alves, L.C., Barreiros, A., Araujo, F., Bohic, S. and Simionovici, A. (2003) Imaging and Quantification of Trace Metals in Thin biological Specimen Using Microprobe Techniques. Synchrotron Induced X-ray Fluorescence Microprobe and Nuclear Microprobe. Journal de Physique IV, 104, 325 .

2 Dalconi, M.C., Meneghini, C., Nuzzo, S., Wenk, R. and Mobilio, S. (2003) Structure of Biopatite in Human Fotal Bones: an X-ray Diffraction Study. Nuclear Instruments and Methodes in Physics Research B, 200, 406.

3 Kruijver, S.O., Zhao, L., Sietsma, J., Offerman, S.E., van Dijk, N.H., Lauridsen, E.M., Margulies, L., Grigull, S., Poulsen, H.F. and van der Zwaag, S. (2003) In Situ Observations on the Mechanical Stability of Austenite in TRIP-Steel. Journal de Physique IV, 104, 499.

4 Salvo, L., Cloetens, P., Maire, E., Zabler, S., Blandin, J.J., Buffière, J.Y., Ludwig, W., Boller, E., Bellet, D. and Josserond, C. (2003), X-ray Micro-Tomography an Attractive Characterisation Technique in Materials Science. Nuclear Instruments and Methodes in Physics Research B, 200, 273.

5 Coles, M.E., Hazlett, R.D., Muegge, E.L., Jones, K.W., Andrews, B., Dowd, B., Siddons, P., Peskin, A., Spanne, P. and Soll, W. (1998) Developments in Synchrotron X-ray Microtomography with Applications to Flow in Porous Media. SPE Reservoir Evaluation and Engineering, 1, 288.

6 Dingenouts, N., Merkle, R., Guo, X., Narayanan, T., Goerigk, G. and Ballauff, M. (2003) Use of Anomalous Small-Angle X-ray Scattering for the Investigation of Highly Charged Colloids. Journal of Applied Crystallography, 36, 578.

7 Breiby, D.W., Samuelsen, E.J., Konovalov, O. and Struth, B. (2003) Drying Behaviour of Thick Poly(Octytiophene) Solutions. Synthetic Metals, 135-136, 345.

8 Lynch, J., Everlien, G., Leblond, C. and Bazin, D. (1999) Evolution of Sulfur During Pyrolysis of Petroleum Kerogens. Journal of Synchrotron Radiation, 6, 661.

9 Sarret, G., Mongenot, T., Connan, J., Derenne, S., Kasrai, M., Bancroft, G.M. and Largeau, C. (2002) Sulfur Speciation in Kerogens of the Orbagnoux Deposit (Upper Kimmeridgian, Jura) by XANES Spectroscopy and Pyrolysis. Organic Geochemistry, 33, 877.

10 Beaucage, G., Kammler, H.K., Mueller, R., Strobel, R., Agashe, N., Pratsinis, S.E. and Narayanan, T. (2004) Probing the Dynamics of Nano-Particle Growth in a Flame Using Synchrotron Radiation. Nature Materials, 3, 370.

11 di Fabrizio, E., Cabrini, S., Cojoc, D., Romanato, F., Businaro, L., Altissimo, M., Kaulich, B., Wilhein, T., Susini, J., de Vittorio, M., Vitale, E., Gigli, G. and Cingolani, R. 
(2003) Shaping X-rays by Diffractive Coded Nano-Optics. Microelectronic Engineering, 67-68, 87.

12 Lamberti, C., Prestipino, C., Bonino, F., Capello, L., Bordiga, S., Spoto, G., Zecchina, A., Diaz-Moreno, S., Cremaschi, B., Garilli, M., Marsella, A., Carmello, D., Vidotto, S. and Leofanti, G. (2002) The Chemistry of Oxychlorination Catalyst: an In Situ, Time-Resolved XANES Study. Angewandte Chemie International Edition English, 41, 2341.

13 Ressler, T., Wienold, J., Jentoft, R.E. and Neisius, T. (2002) Bulk Structural Investigation of the Reduction of $\mathrm{MoO}_{3}$ with Propene ant the Oxidation of $\mathrm{MoO}_{2}$ with Oxygen. Journal of Catalysis, 210, 67.

14 Fiddy, S.G., Evans, J., Newton, M.A., Neisius, T., Tooze, R.P. and Oldman, R.J. (2003) Extended X-ray Absorption Fine Structure (EXAFS) Characterisation of Dilute Palladium Homogeneous Catalysts. Chemical Communications, 15, 2682.

15 Battiston, A.A., Bitter, J.H., de Groot, F.M.F., Overweg, A.R., Stephan, O., van Bokhoven, J.A., Kooyman, P.J., van der Spek, C., Vanko, G. and Konigsberger, D.C. (2003) Evolution of Fe Species During the Synthesis of OverExchanged Fe/ZSM5 Obtained by Chemical Vapor Deposition of $\mathrm{FeCl}_{3}$. Journal of Catalysis, 213, 251.

16 Elder, F., Gurewitsch, A.M., Langmuir, R.V. and Pollock, H.C. (1947) Phys. Rev., 71, 829.

17 Elder, F., Gurewitsch, A.M., Langmuir, R.V. and Pollock, H.C. (1947) J. Appl. Phys., 18, 810.

18 Elder, F., Langmuir, R.V. and Pollock, H.C. (1948) Radiation from Electrons Accelerated in a Synchrotron. Phys. Rev., 74, 52.

19 Ado, I.M. and Cherenkov, P.A. (1956) Sov. Phys. Dokl., 1, 517.

20 Corson, D.A. (1952) Radiation Loss by Electrons in Large Orbits. Phys. Rev., 86, 1052.

21 Hartman, P.L. and Tomboulian, D.H. (1952) Phys. Rev., 87, 233.

22 Hartman, P.L. and Tomboulian, D.H. (1953) Far Ultraviolet Radiation from the Cornell Synchrotron. Phys. Rev., 91, 1577.

23 Coster, D. (1924) Z. Phys., 25, 83.

24 Lindh, A.E. (1925) Z. Phys., 31, 210.

25 Sayers, D.E., Stern, E.A. and Lytle, F.W. (1971) New Technique for Investigating Noncrystalline Structures: Fourier Analysis of the Extended X-Ray-Absorption Fine Structure. Phys. Rev. Lett., 27, 1204.

26 Farge, Y., Thompson, D.J. and Buras, B. (1979) ESRF: The Feasibility Study. European Science Foundation, Strasbourg.

27 Einsenberger, P. and Knotek, M. (1984) Planning Study for Advanced National Synchrotron-Radiation Facilities. Department of Energy, Office of Basic Energy Sciences, Washington DC.

28 Proceedings of the Workshop for a $1 \AA$ Free Electron Laser, Sag Harbor, New York, April (1990).

29 Proceedings of the International Workshop on X-Ray Free Electron Laser Application, DESY, Hamburg, September (1996).

30 SASE FAL at the Tesla Test Facility, Phase 2, TESLA FEL 2002-01, DESY, Hamburg (2002).

31 Winick, H. and Doniach, S. (1980) Synchrotron Radiation Research, Plenum Press, New York.

32 Sham, T.K. and Rivers, M.L. (2002) A Brief Overview of Synchrotron Radiation. Reviews in Mineralogy and Geochemistry, 49, 117.
33 Winick, H. (1994) Synchrotron Radiation Sources, a Primer. World Scientific, Singapore.

34 Wille, K. (2000) The Physics of Particule Accelerators, an Introduction, Oxford University Press, Oxford, UK.

35 Elleaume, P. (2004) Future Storage Ring Synchrotron Sources, AIP Conference Proceedings, 705, 149.

36 Proux, O., Biquard, X., Lahera, E., Menthonnex, J.J., Prat, A, Ulrich, O., Soldo, Y., Trévisson, P., Kapoujvan, G., Perroux, G. Taunier, P., Grand, D., Jeantet, P., Deleglise, M., Roux, J.P. and Hazemann, J.L. FAME: A New Beamline for X-ray Absorption Investigations of Very-Diluted Systems of Environmental, Material and Biological Interests Physica Scripta to be published.

37 Gailhanou, M., Dubuisson, J.M., Ribbens, M., Roussier, L., Bétaille, D., Créoff, C., Lemonnier, M., Denoyer, J., Bouillot, D., Jucha, A., Lena, A., Idir, M., Bessière, M., Thiaudière, D., Hennet, L., Landron, C. and Coutures, J.P. (2001) H10: a materials and high temperature beamline at DCI/LURE. NIM A, 467-468, 745-747.

38 Cernik, J.R., Barnes, P., Bushnell-Wye, G., Dent, A.J., Diakun, G.P., Flaherty, J.V., Greaves, G.N., Heeley, E.L., Helsby, W., Jacques, S.D.M., Kay, J., Rayment, T., Ryan, A., Tang, C.C. and Terrill, N.J. (2004) The New Materials Processing Beamline at the SRS Daresbury, MPW6.2. Journal of Synchrotron Radiation, 11, 163.

39 Fitch, A.N. (2004) The High Resolution Powder Diffraction Beam Line at ESRF. Journal of the National Institute of Standards and Technology, 109, 133.

40 Konovalov, O. (2004) Troika II (ID10B): A Versatile Beamline for Studies of Liquid and Solid Interfaces. Conference Proceedings 8. International Conference on Synchrotron Radiation Instrumentation, San Francisco, 705, 352.

41 Ohana, J., Jacquamet, L., Joly, J., Bertoni, A., Taunier, P., Michel, L., Charrault, P., Pirocchi, M., Carpentier, P., Borel, F., Khan, R. and Ferrer, J.L. (2004) CATS: A Cryogenic Automated Transfer System Installed on the Beamline FIP at ESRF. Journal of Applied Crystallography, 37, 72.

42 Pohl, E., Ristau, U., Gehrmann, T., Jahn, D., Robrahn, B., Malthan, D., Dobler, H. and Hermes, C. (2004) Automation of the EMBL Hamburg Protein Crystallography Beamline BW7B. Journal of Synchrotron Radiation, 11, 372.

43 Sutton, D., Hanley, T., Knott, R. and Cookson, D. (2004) Small-Angle X-ray Scattering on the ChemMatCARS Beamline at the Advanced Photon Source: A Study of ShearInduced Crystallization in Polypropylene. Journal of Synchrotron Radiation, 11, 505.

44 Winick, H. and Brown, G. (1978) Workshop on X-Ray Instrumentation for Synchrotron Radiation Research, SSRL Report 78/04

45 Wuilleumier, F. and Farge, Y. (1978) Proceedings of the International Conference on Synchrotron Radiation Instrumentation and New Developpements, Orsay, France, NorthHolland Publishing Co., Amsterdam.

46 Franks, A. (1977) X-Ray Optics, Sci. Prog. (London), 64, 371.

47 Sakayanagi, Y. and Aoki, S. (1978) Soft X-Ray Imaging with Toroidal Mirrors. Appl. Opt., 17, 601.

48 from http:Ilesrf.fr.

49 Schwinger, J. (1949) Phys. Rev., 75, 1912.

50 Tomboulian, D.H. and Hartman, P.L. (1956) Phys. Rev., 102, 1423.

51 Godwin, R.P. (1968) Springer Tracts Mod. Phys., 51, 1.

52 Sokolov, A.A. and Ternov, I.M. (1968) Synchrotron Radiation, Pergamon, New York. 
53 Jackson, J.D. (1975) Classical Electrodynamics, Chapter 14, 848.

54 Koch, E.E. (1983) Handbook on Synchrotron Radiation, North-Holland Publishing Company.

55 Shenoy, G.K. (2004) Advanced Photon Source: Science Retrospect and Prospect. Radiation Physics and Chemistry, 70 (4-5), 619 .

56 Mulhaupt, G. and Ruffer, R. (1999) Properties of Synchrotron Radiation. Hyperfine Interactions, 123 (1-8), 13.

57 Ropert, A. (1994) Overview of the Challenges of the NewGeneration of Synchrotron Light-Sources. Journal de Physique IV, 4 (C9), 365.

58 Elemental Speciation, New Approches for Trace Element Analysis, Carruso, J.R., Sutton, K.L. and Ackley, K.L. (eds), Comprehensive Analytical Chemistry, XXXIII (2000) Elsevier.

59 Baumert, J., Gutt, C., Shpakov, V.P., Tse, J.S., Krisch, M., Müller, M., Requardt, H., Klug, D.D., Janssen, S. and Press, W. (2003) Lattice Dynamics of Methane and Xenon Hydrate: Observation of Symmetry-avoided Crossing by Experiment and Theory. Phys. Rev. B, 68, 174301.

60 Shen, G., Rivers, M.L., Wang, Y. and Sutton, S.R. (2001) Laser Heated Diamond Cell System at the Advanced Photon Source for In Situ X-ray Measurements at High Pressure and Temperature. Rev. Sci. Inst., 72, 1273.

61 Rosenberg, E., Lynch, J., Guéroult, P., Bisiaux, M. and Ferreira-de-Paiva, R. (1999) High Resolution 3D Reconstructions of Rock and Composites. Oil \& Gas Sci. and Technol., 54, 497.

62 Schutz, R.W., Baxter, C.F. and Boster, P.L. (2001) Applying Titanium Alloys in Drilling and Offshore Production Systems. JOM, 53, 33.

63 Deng, C.S., Breen, C., Yarwood, J., Habesch, S., Phipps, J., Craster, B. and Maitland, G. (2002) Ageing of Oilfield Cement at High Humidity: a Combined FEG-ESEM and Raman Microscopic Investigation. J. Mater. Chem., 10, 3105.

64 Sinquin, A., Palermo, T. and Peysson, Y. (2004) Rheological and Flow Properties of Gas Hydrate Suspensions. Oil \& Gas Sci. and Technol., 59, 41.

65 Espinat, D. and Ravey, J.C. (1993) Colloidal Structure of Asphaltene Solutions and Heavy-Oil Fractions Studied by Small-Angle Neutron and X-ray Scattering. SPE 25187, SPE International Symposium on Oilfield Chemistry, New Orleans, LA, March 2-5.

66 Fine, T., Sautereau, H. and Sauvant-Moynot, V. (2003) Innovative Processing and Mechanical Properties of High Temperature Syntactic Foams Based on a Thermoplastic/ Thermoset Matrix, J. Mater. Sci., 38, 2709.

67 Elmoutaouakkil, A., Fuchs, G., Bergounhon, P., Péres, R. and Peyrin, F. (2003) Three-Dimensional Quantitative Analysis of Polymer Foams from Synchrotron Radiation X-ray Microtomography. J. Phys. D: Appl. Phys., 36, A37.

68 Langevin, D., Poteau, S., Hénaut, I. and Argillier, J.F. (2004) Crude Oil Emulsion Properties and their Application to Heavy Oil Transportation. Oil \& Gas Sci. and Technol., 59, 511.
69 Dwiggins, C.W. (1978) Study of Colloidal Nature of Petroleum with an Automated Bonse-Hart X-ray SmallAngle Scattering Unit. J. Appl. Cryst., 11, 615.

70 Spiecker, P.M., Gawrys, K.L., Trail, C.B. and Kilpatrick, P.K. (2003) Effects of Petroleum Resins on Asphaltene Aggregation and Water-in-Oil Emulsion Formation. Colloids and Surfaces A: Physicochem. Eng. Aspects, 220, 9.

71 Zhang, X., Chodakowski, M. and Shaw, J.M. (2004) Dynamic Interfacial Zone and Local Phase Concentration Measurements in Emulsions, Dispersions and Slurries. J. Dispersion Sci. and Techn., 25, 277.

72 Butler, L.G., Ham, K., Jin, H. and Kurtz, R.L. (2002) Tomography at the Louisiana State University CAMD Synchrotron: Applications to Polymer Blends in Developments in X-Ray Tomography III, Bonse, U. (ed). Proc. SPIE, 4503, 54.

73 Cerny, R. (1996) Structure of Metal Hydrides from X-ray, Synchrotron and Neutron Powder Diffraction. Materials Science Forum, 228-231, 667.

74 Lynch, J., Everlien, G., Leblond, C. and Bazin, D. (1999) Evolution of Sulfur During Pyrolysis of Petroleum Kerogens. J. Synchrotron Rad., 6, 661.

75 Fafet, A., Bonnard, J. and Prigent, F. (1999) New Developments in Mass Spectrometry for Group-Type Analysis of Petroleum Cuts. Oil \& Gas Sci. and Technol., 54, 439.

76 Toulhoat, H. and Raybaud, P. (2003) Kinetic Interpretation of Catalytic Activity Patterns Based on Theoretical Chemical Descriptors. J. Catal., 216, 63.

77 Weitkamp, J. and Hunger, M. (2001) In Situ IR, NMR, EPR, and UV/Vis Spectroscopy: Tools for New Insight into the Mechanisms of Heterogeneous Catalysis. Angewandte Chemie Int. Ed., 40, 2954.

78 See articles in the special issue (2001) of Catalysis Today, 70, 1-284.

79 Lynch, J. (2002) Development of Structural Characterisation Tools for Catalysts. Oil \& Gas Sci. and Technol., 57, 281.

80 Khodakov, A.Y., Lynch, J., Bazin, D., Rebours, B., Zanier, N., Moisson, B. and Chaumette, P. (1997) J. Catal., 168, 16.

81 Goerigk, G., Haubold, H.G., Lyon, O. and Simon, J.P. (2003) Anomalous Small-angle X-ray Scattering in Materials Science. J. Appl. Cryst., 36, 425.

82 Bazin, D., Lynch, J. and Ramos-Fernande, M. (2003) X-ray Absorption Spectroscopy and Anomalous Wide Angle X-ray Scattering: Two Basic Tools in the Analysis of Heterogeneous Catalysts. Oil \& Gas Sci. and Technol., 58, 667.

83 http://www.esrf.fr/NewsAndEvents/Spotlight/spotlight1_volpe/

84 Tromp, M., van Bokhoven, J.A., van Haaren, R.J., van Strijdonck, G.P., van der Eerden, A.M., van Leeuwen, P.W. and Koningsberger, D.C. (2002) Structure-Performance Relations in Homogeneous Pd Catalysis by In Situ EXAFS Spectroscopy. J. Am. Chem. Soc., 124, 14814.

85 Noiriel, C., Bernard, D., Gouze, Ph. and Thibault, X. (2005) Hydraulic Properties and Microgeometry Evolution Accompanying Limestone Dissolution by Acidic Water. Oil \& Gas Sci. and Technol., 60, 177.

Final manuscript received in July 2005

\section{Copyright $(9) 2005$ Institut français du pétrole}

Permission to make digital or hard copies of part or all of this work for personal or classroom use is granted without fee provided that copies are not made or distributed for profit or commercial advantage and that copies bear this notice and the full citation on the first page. Copyrights for components of this work owned by others than IFP must be honored. Abstracting with credit is permitted. To copy otherwise, to republish, to post on servers, or to redistribute to lists, requires prior specific permission and/or a fee. Request permission from Documentation, Institut français du pétrole, fax. +33147527078 , or revueogst@ifp.fr. 